SHORT COMMUNICATION

\title{
Preparation of Layer-by-layer Thin Films Containing Insulin and its pH-Sensitive Decomposition
}

\author{
By Kentaro Yoshida, Hiroshi SATO, Shigehiro TAKAHASHI, and Jun-ichi ANZAI*
}

KEY WORDS: Insulin / Controlled Release / Layer-by-layer / Thin Film /

\begin{abstract}
A layer-by-layer (LbL) deposition technique has been widely used for preparing layered thin films by taking advantage of the electrostatic force of attraction, hydrogen bonding, and biological affinity between synthetic polymers, proteins, polysaccharides, etc. ${ }^{1-5}$ The layered thin films have found applications in optical and electronic devices, sensors, and separation and purification. ${ }^{6-9}$

Recently, much attention has been devoted to the development of LbL films and microcapsules for controlled release of insulin. ${ }^{10,11}$ Lyon and coworkers have developed insulin-doped LbL thin films using a thermosensitive poly ( $N$-isopropylacrylamide) derivative for thermally modulated insulin delivery. ${ }^{12}$ Biodegradable polymers have also been used for preparing insulin-containing LbL films and capsules for sustained release of insulin. ${ }^{13}$ One of the focal subjects in insulin delivery is the development of insulin formulations that can be orally administrated. For this goal, insulin formulations have to be stable at acidic $\mathrm{pH}$ in the stomach, while insulin can be released at the neutral $\mathrm{pH}$ in the intestine where insulin is adsorbed. In fact, many kinds of $\mathrm{pH}$-sensitive polymers have been employed as enteric coatings for developing oral formulations of insulin. ${ }^{14,15}$ However, no attempt has appeared on the use of LbL films for developing insulin formulations that can be orally administrated. In the present study, we have successfully prepared insulin-containing LbL films that are stable at acidic $\mathrm{pH}$ and decomposed at $\mathrm{pH}$ 7.4. The present communication reports a preliminary result on the $\mathrm{pH}$-triggered release of insulin from the LbL thin films.
\end{abstract}

\section{EXPERIMENTAL}

\section{Materials}

Insulin (human, recombinant) was purchased from Wako Pure Chemicals Industries Ltd. Poly(acrylic acid) (PAA, MW:8,000-12,000, Wako Pure Chemical Ind.), poly(vinyl sulfate) (PVS, MW:240,000, Nakalai Tesque Co.), dextran sulfate (DS, MW:25,000, Tokyo Kasei Co.), and poly(ethyleneimine) (PEI, MW:60,000-80,000, Nakalai Tesque Co.) are commercial products and used without further purification.

\section{Preparation of Insulin-containing LbL Films}

A quartz crystal microbalance (QCM) (440E QCM, BAS, Tokyo) was employed for the gravimetric analysis of LbL films. A 8-MHz AT-cut quartz resonator coated with a thin Au layer (geometric surface area, $0.20 \mathrm{~cm}^{2}$ ) was used as a probe, in which the adsorption of one $\mathrm{ng}$ of substrate induces $c a .-0.75 \mathrm{~Hz}$ change in the resonance frequency. The quartz resonator was mounted in a flow cell and the surface was exposed to $1 \mathrm{mg} / \mathrm{mL}$ PEI solution in water for $15 \mathrm{~min}$ to deposit a first PEI layer. The PEI-modified quartz resonator was exposed to $0.5 \mathrm{mg} / \mathrm{mL}$ polyanion in $10 \mathrm{mM}$ citrate buffer containing $150 \mathrm{mM} \mathrm{NaCl}(\mathrm{pH} \mathrm{3.0)}$ ) for $15 \mathrm{~min}$ and rinsed with the working buffer for $5 \mathrm{~min}$. The polyanion-deposited quartz resonator was then exposed to $0.2 \mathrm{mM}$ insulin solution in the citrate buffer at $\mathrm{pH} 3.0$ for $15 \mathrm{~min}$ and rinsed with the buffer for $5 \mathrm{~min}$. The alternate deposition was repeated to prepare LbL films and the resonance frequency of the quartz resonator was recorded after each deposition. For the spectrophotometric determination of the loading of insulin in the LbL films, LbL films were prepared on the both surfaces of a quartz slide $(50 \times$ $10 \times 1 \mathrm{~mm})$ in a similar manner.

\section{pH-Triggered Decomposition of Insulin-containing Films}

The surface of the LbL film-coated quartz resonator was exposed to a $10 \mathrm{mM}$ Tris- $\mathrm{HCl}$ buffer containing $150 \mathrm{mM} \mathrm{NaCl}$ at $\mathrm{pH} 7.4$ and the resonance frequency was monitored. All experiments were carried out at room temperature $\left(\mathrm{ca} .20^{\circ} \mathrm{C}\right)$.

\section{RESULTS AND DISCUSSION}

Figure 1 shows a typical QCM result for the preparation of a PVSinsulin LbL film at $\mathrm{pH} 3.0$ and its decomposition at $\mathrm{pH}$ 7.4. The resonance frequency $(\mathrm{F})$ was decreased when the quartz resonator was exposed to the PVS and insulin solutions at $\mathrm{pH} 3.0$, suggesting a successful deposition of PVS and insulin on the surface of the quartz resonator. It is likely that a positively charged insulin and anionic PVS are alternately adsorbed on the surface of the quartz resonator, through an electrostatic force of attraction, to form the LbL thin film. This is reasonable because the isoelectric point (pI) of insulin is $5.4^{16}$ and sulfonate residues in PVS are negatively charged at $\mathrm{pH}$ 3.0. In contrast, the resonance frequency increased quickly back to the original value before deposition of insulin upon charging a Tris- $\mathrm{HCl}$ buffer ( $\mathrm{pH}$ 7.4) into the flow cell, suggesting the LbL film was decomposed due to an electrostatic repulsion between negatively charged insulin and PVS in the film. It was also found that the PVS-insulin LbL films can be formed at $\mathrm{pH} 1.0$ and 2.0, while the LbL film did not form when the solutions of $\mathrm{pH} 7.4$ were used. We have employed also PAA and DS as polyanionic materials to prepare insulin-containing LbL films and found that both PAA-insulin and DS-insulin films can be prepared at $\mathrm{pH} 3.0$ in a similar manner and the films are decomposed at the neutral $\mathrm{pH}$. Thus, it has clearly been demonstrated that insulin-containing LbL films can be prepared using suitable polyanions at acidic $\mathrm{pH}$ and, at $\mathrm{pH}$ 7.4, insulin is released. It should be noted here that the decomposition of the LbL film at $\mathrm{pH} 7.4$ is rapid probably due to the LbL structure of the film.

The stability of PVS-insulin LbL film at $\mathrm{pH} 1.0$ (stomach $\mathrm{pH}$ ) was evaluated by monitoring frequency changes in QCM and no frequency change was observed for $c a .60 \mathrm{~min}$, showing that the LbL film is stable in the acidic medium. A threshold $\mathrm{pH}$ for the decomposition of the PVSinsulin film was found to be $\mathrm{pH}$ 5.0-5.5. This is nearly the same value as $\mathrm{pI}$ of insulin, suggesting that the decomposition of the LbL films is originating from the negative charges on insulin. Interestingly, the threshold $\mathrm{pH}$ of PAA-based films was slightly acidic than $\mathrm{pH} 5.0$, probably due to a lower acidity of PAA than those of PVS and DS.

It is interesting to evaluate the loading of insulin in the LbL films from the view point of future application of the films to insulin delivery. For this reason, we have tried to evaluate UV-visible absorption of the LbL films which were prepared on an optically transparent quartz slide. Unfortu- 


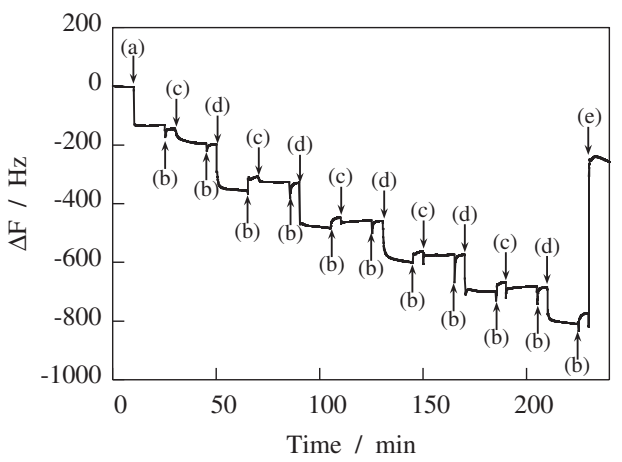

Figure 1. A typical QCM response for the preparation of PVS-insulin LbL film at $\mathrm{pH} 3.0$ and its decomposition at $\mathrm{pH}$ 7.4. The quartz resonator was exposed to PEI (a), PVS (c), and insulin solutions (d). At b and e, the film was rinsed with buffers at $\mathrm{pH} 3.0$ and 7.4, respectively.

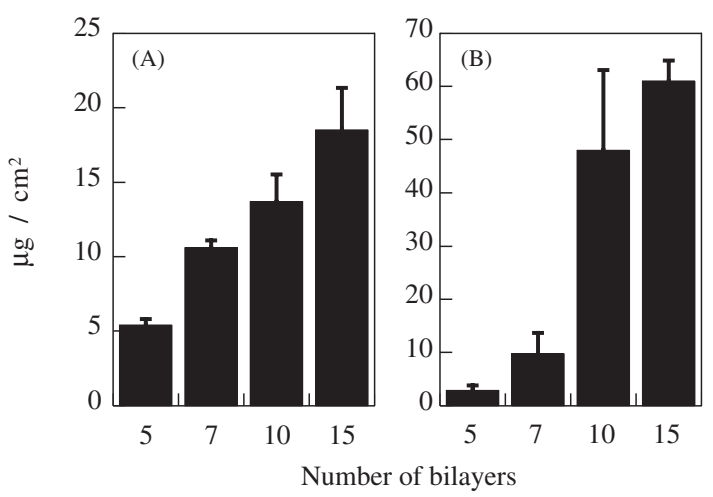

Figure 2. The loading of insulin in the PVS-insulin (A) and PAA-insulin LbL films (B) as a function of the number of layers. The average values of three preparations are shown.

nately, however, the insulin-containing LbL films were slightly cloudy and not suitable for recording UV-visible absorption spectrum. Therefore, the loading of insulin in the LbL films was determined from the absorbance at $280 \mathrm{~nm}$ of the buffer solution after the LbL films were fully dissolved in the buffer at $\mathrm{pH}$ 7.4. Figure 2 shows the loading of insulin in the films as a function of the number of layers in the films. The loading of insulin in the LbL films increased with the increasing number of layers. It may be interesting to note that the loading of insulin in the PVS-insulin films is proportional to the number of layers, while, in the PAA-insulin films, the deposited amount of insulin in the outer layers is higher than that in the inner layers. In other words, the loading of insulin can be regulated by a suitable choice of polymeric materials used.

It is known that insulin consists of two polypeptide chains composed of 51 amino acids and the polypeptide chains are dominated by $\alpha$-helical segments. ${ }^{17,18}$ It may be important to evaluate the conformation of insulin after being released from the LbL films. For this purpose, we have recorded a circular dichroism (CD) spectrum of insulin in the Tris- $\mathrm{HCl}$ buffer at $\mathrm{pH} 7.4$ after decomposition of PVS-insulin LbL film. The CD spectrum showed typical $\alpha$-helical characteristics with strong negative ellipticity at 208 and $222 \mathrm{~nm}$, which is completely superimposed to the CD spectrum of native insulin. These observations clearly suggest that virtually no conformational change is induced in the polypeptide chains during the deposition into the LbL films in the acidic medium.

In summary, we have demonstrated that insulin thin films can be prepared by an alternate deposition of polyanion and insulin at $\mathrm{pH} 1.0-3.0$ and insulin can be released at $\mathrm{pH}$ 7.4. The present LbL films may be useful for future applications to the development of oral formulations of insulin.

Received: September 4, 2007

Accepted: October 29, 2007

Published: December 11, 2007

\section{REFERENCES}

1. G. Decher and J.-D. Hong, Makromol. Chem. Makromol. Symp., 46, 321 (1991)

2. Y. Lvov, K. Ariga, I. Ichinose, and T. Kunitake, J. Am. Chem. Soc., 117, 6117 (1995)

3. J. Anzai, Y. Kobayashi, N. Nakamura, M. Nishimura, and T. Hoshi, Langmuir, 15, 221 (1999).

4. S. A. Sukhishvili and S. Granick, Macromolecules, 35, 301 (2002).

5. S. A. Sukhishvili, E. Kharlampieva, and V. Izumrudov, Macromolecules, 39, 8873 (2006).

6. K. Ariga, J. P. Hill, and Q. Ji, Phys. Chem. Chem. Phys., 9, 2319 (2007).

7. T. Hoshi, J. Anzai, and T. Osa, Anal. Chem., 67, 770 (1995).

8. J. Anzai, H. Takeshita, Y. Kobayashi, T. Osa, and T. Hoshi, Anal. Chem., 70, 811 (1998).

9. T. Hoshi, H. Saiki, S. Kuwazawa, C. Tsuchiya, Q. Chen, and J. Anzai, Anal. Chem., 73, 5310 (2001).

10. Z. F. Dai, A. Heilig, H. Zastrow, E. Donath, and H. Möhwald, Chem. Euro. J., 10, 6369 (2004).

11. S. Ye, C. Wang, X. Liu, Z. Tong, B. Ren, and F. Zeng, J. Controlled Release, 112, 79 (2006).

12. C. M. Nolan, M. J. Serpe, and L. A. Lyon, Biomacromolecules, 5, 1940 (2004).

13. Y. F. Fan, Y. N. Wang, Y. G. Fan, and J. B. Ma, Int. J. Pharm., 324, 158 (2006)

14. G. P. Carino and E. Mathiowiz, Adv. Drug Delivery Rev., 35, 249 (1999).

15. B. Kim and N. A. Peppas, Int. J. Pharm., 266, 29 (2003).

16. F. Cui, K. Shi, L. Zhang, A. Tao, and Y. Kawashima, J. Controlled Release, 114, 242 (2006)

17. N. A. Peppas and N. J. Kavimandan, Euro. J. Pharm. Sci., 29, 183 (2006).

18. S. H. Mollmann, L. Jorgensen, J. T. Bukrinsky, U. Eiofsson, W. Norde, and S. Frokjaer, Euro. J. Pharm. Sci., 27, 194 (2006). 